\title{
(2) OPEN ACCESS \\ Attitudes and perceived barriers to mental healthcare in the People's Liberation Army Navy: study from a navy base
}

\author{
Ren-Ping Gu $\odot$, X R Liu, X F Ye
}

Faculty of Military Health Service, Second Military Medical University, Shanghai, China

\section{Correspondence to} Ren-Ping Gu, Faculty of Military Health Service, Second Military Medical University, Shanghai 200433, China; gurenping2000@aliyun.com

Received 19 December 2019 Revised 21 April 2020 Accepted 26 April 2020

\section{Check for updates}

(c) Author(s) (or their employer(s)) 2020. Re-use permitted under CC BY-NC. No commercial re-use. See rights and permissions. Published by BMJ.

To cite: Gu R-P, Liu XR, Ye XF. BMJ Mil Health Epub ahead of print: [please include Day Month Year]. doi:10.1136/

jramc-2019-001396

\section{ABSTRACT}

Introduction The People's Liberation Army (PLA, China) Navy is increasingly conducting military operations other than war overseas. Factors such as confrontations with pirates, special environments and long sailing times have resulted in mental health problems. However, the navy's actual utilisation of mental health services is low. This study examined members' rate of willingness to seek help and the factors that act as barriers to willingness to seek mental health services in the PLA Navy.

Methods This cross-sectional study was conducted at the Zhoushan Base, operated by the East Sea Fleet, between March 2019 and April 2019. We distributed a 12-item questionnaire to examine participants' attitudes and perceived barriers to mental healthcare. We recruited 676 navy personnel. Participants' willingness to seek help if they had mental health problems was also assessed.

Results The response rate was $99 \%$. A total of $88.44 \%$ of the sample reported being willing to seek help. Univariate analysis suggested that those not willing to seek help were more likely to agree with the items, 'Mental healthcare does not work' and 'My unit leadership might treat me differently' and all organisational barriers, and they were more likely to have concerns about 'embarrassment' and 'being weak' than those willing to seek help. After controlling for demographic characteristics, binary logistic regression analyses confirmed that a lack of knowledge regarding the location of mental health clinics and being perceived as weak were the main factors preventing participants' willingness from seeking help.

Conclusions Extensive efforts to decrease organisational barriers and stigma towards mental healthcare should be a priority for researchers and policymakers to improve the usage of mental health services. Psychoeducation aimed at de-stigmatising mental health problems should be delivered and the accessibility and availability of mental health services should be increased.

\section{INTRODUCTION}

Exposure to deployment-related stressors-such as taking enemy fire, handling dead bodies, knowing someone who was killed, or killing enemy combatants-are strongly related to the prevalence of post-traumatic stress disorder (PTSD). ${ }^{1}$ Historically, there has been a sharp increase in the number of evacuated soldiers with mental disorders. ${ }^{2-6}$ In a previous study, approximately one-third of soldiers experienced mental health problems about 6 months after returning from deployment. ${ }^{7}$ The US Department of Defence has made extensive efforts to enhance access to mental health services for

\section{Key messages}

PLA Navy members completed a questionnaire on barriers to mental healthcare.

- Most participants were willing to seek help for mental health problems.

- A lack of knowledge regarding the location of mental health clinics and being perceived as weak were the main barriers to mental healthcare.

- Extensive efforts to decrease organisational barriers and stigma toward mental healthcare should be a priority for researchers and policymakers.

military personnel, including enhancing screening for mental health issues before and after deployment,${ }^{8}$ conducting psychological evaluations and interventions for soldiers who have experienced war $^{7}$ and paying close attention to veterans' mental health. ${ }^{9}$ However, studies have consistently found that only a fraction of those with symptoms of mental illness seek care/help, and few soldiers are interested in receiving help, which is inconsistent with the expected prevalence of mental disorders and their needs. For example, Hoge showed that only $23 \%-40 \%$ of soldiers and marines with symptoms of mental illness sought mental healthcare, and less than half were interested in receiving mental healthcare. ${ }^{1}$ In another study, among soldiers who received a PTSD diagnosis within 90 days of returning from Afghanistan, 22\% had only attended one mental healthcare visit. ${ }^{10}$

What prevents military personnel from seeking mental healthcare? To understand this, Hoge and colleagues $^{1}$ developed a 13 -item questionnaire concerning perceived barriers to mental health services. The barriers covered by the instrument included concerns about how a soldier will be perceived by their peers and leaders, fears of harming their military career, lack of trust in mental health professionals and organisational barriers (eg, difficulty in scheduling an appointment, getting time off for treatment and the cost of mental healthcare). Since then, it has been widely used in various forms with US $^{11-14}$ and British ${ }^{15}$ military personnel according to the purposes of the study being conducted.

The Chinese People's Liberation Army (PLA) is the military of the People's Republic of China. It includes ground, naval, air, rocket, strategic 
support and joint logistic support forces. The PLA Navy is the naval branch of the PLA. The PLA Navy force is organised into three fleets: the North Sea Fleet, East Sea Fleet and South Sea Fleet. Each fleet owns and operates several bases. For the past 40 years, China has not been engaged in war. Owing to broadening maritime interests and the naval strategic transformation, the PLA Navy is increasingly conducting military operations other than war overseas. Factors such as confrontations with pirates, special environments (eg, airtightness, high temperature, noise aboard ships) and long sailing times have resulted in mental health problems. ${ }^{16} 17$

Over the past decade, the PLA has steadily promoted mental health service at all levels, and studies aiming to explore the mental health characteristics of Chinese service people have been conducted. Every regiment has its own mental health clinic with at least one mental health worker. Psychological education is an important way to improve psychological health and boost morale. Psychological education in the military applies multidisciplinary theories, psychological methods and techniques, pedagogy, sociology and psychiatry to cultivate favourable psychological features in military personnel, to improve their psychological functioning and help them reach their full psychological potential. The objective of psychological education is to resolve psychological conflicts, relieve psychological pressure, strengthen psychological quality, develop a well-rounded personality, reduce and prevent mental illness and maintain a healthy state of mind. Many mental health instruments are used to assess the mental health status of Chinese soldiers. Even while at sea, the navy can conduct psychological counselling through the Political Work Website, a network platform for the navy to perform political work. It offers featured columns, such as political education, current affairs, online legal services and psychological counselling. All soldiers can communicate with psychological counsellors online at any given time, regardless of their location. Despite these efforts, the actual utilisation of mental health services is low. A previous study found that, out of 1204 PLA Navy members who reported a stress problem, only $26.7 \%$ were seeking help. ${ }^{18}$ However, there has been no related research on the factors behind this low rate of seeking psychological help. In addition, research assessing the attitudes and perceived barriers to mental healthcare in the Chinese Army has been scarce. Furthermore, the increase in utilisation of psychological services is based on the premise of an increase in willingness to seek help. Understanding the influencing factors of soldiers' willingness to seek mental health may help providers develop new ways to encourage soldiers to use the services available to them.

This study investigated two main research questions: (1) What is the rate of willingness to seek help when experiencing a mental health problem in the Chinese Navy? and (2) What are the prevailing perceived barriers to willingness to seek mental health services in the Chinese Navy?

\section{MATERIALS AND METHODS}

\section{Data collection}

Data for this study were collected from the Zhoushan Base, operated by the East Sea Fleet, which performs certain combat missions around the East Sea areas. Data were collected between March 2019 and April 2019. Base leaders assembled the Navy Corps near their workplaces at convenient times. The intended sample size was all personnel on all the vessels during the visit. Reasons for not being available to complete the survey included work-related duties, illness, leave, or temporary duty elsewhere.
In total, 676 naval soldiers convened for this research. After a short recruitment briefing by the researchers, participants voluntarily completed an anonymous questionnaire, which took approximately $10-15$ min to complete. Nearly all $(n=669)$ soldiers chose to participate (response rate=99\%). Prior to participating in the survey, the military personnel provided written informed consent. The data of 649 navy personnel were ultimately used for analysis as we excluded responses with incomplete information.

\section{Measures}

This was a quantitative study involving a cross-sectional selfreport survey. We used the 12 -item questionnaire concerning perceived barriers to mental health services (Cronbach's alpha $=0.889)$, which was taken from Hoge and colleagues, ${ }^{1}$ and has been widely used in various forms with military personnel. The items were translated into Chinese by the authors and backtranslated by two English editors. After that, the items, both in English and Chinese, were sent to four experts (two psychologists, a methodologist and a linguist) in military academic institutions in China to ensure that they were comprehensible considering cultural differences. Each item was scored on a fivepoint Likert-type scale from 1 (strongly disagree) to 5 (strongly agree). Participants were asked to rate how each of the listed concerns would affect their decision to seek mental healthcare if they developed a mental health problem. One question was asked regarding willingness to seek help: 'If you had a mental health problem, would you seek help?' Response options were 'yes' or 'no'. Additionally, the questionnaire included items on background such as demographics and military experience.

\section{Analyses}

We used SPSS V.21.0 for statistical analysis. Frequencies were calculated and $\chi^{2}$ tests were used to assess the difference in each item between participants willing or not willing to seek help. Binary logistic regression analyses, unadjusted and adjusted for potential confounding factors, were further performed to generate ORs with 95\% CIs. The significance level was set at 0.05 .

\section{RESULTS}

\section{Demographic characteristics}

Participants were mostly single Han Chinese men. Most had a college degree. The most common service length was 1-2 years and most were non-commissioned officers (Table 1).

\section{Factors related to willingness to seek help}

In this sample, $88.44 \%$ reported willingness to seek help if they had a mental health problem and $11.56 \%$ reported not being willing to do so. Table 2 depicts the comparison of each item related to attitudes and perceived barriers between participants willing and unwilling to seek help if they had a mental health problem. Those not willing to seek help were more likely to agree with the items, 'Mental healthcare does not work' and 'My unit leadership might treat me differently' as well as all the organisational barriers than those willing to seek help. Those who were not willing to seek help were also more likely to have concerns about 'embarrassment' and 'being weak' than were those willing to seek help.

We performed two binary logistic regression analyses to identify the significant barriers to participants' willingness to seek help. Model 1 included factors with items 2, 3 and 6-12. Model 2 included the variables in Model 1 as well as demographics (age, 
Table 1 Demographic characteristics of study participants

\begin{tabular}{|c|c|c|c|c|c|}
\hline Demographics & $\begin{array}{l}\text { Participants } \\
\mathrm{n}(\%)\end{array}$ & $\begin{array}{l}\text { Willing to seek help } \\
\mathrm{n}(\%) \\
(\mathrm{n}=574)\end{array}$ & $\begin{array}{l}\text { Not willing to seek help } \\
\mathrm{n}(\%) \\
(\mathrm{n}=75)\end{array}$ & $\chi^{2}$ & $P$ value \\
\hline \multicolumn{6}{|l|}{ Sex } \\
\hline Female & $21(3.24)$ & $21(3.66)$ & $0(0)$ & & \\
\hline \multicolumn{6}{|l|}{ Ethnicity } \\
\hline \multicolumn{6}{|l|}{ Education } \\
\hline$\leq$ High school & 215 (33.13) & 187 (32.58) & $28(37.33)$ & 0.677 & 0.411 \\
\hline$\geq$ Some college & $434(66.87)$ & 387 (67.42) & 47 (62.67) & & \\
\hline \multicolumn{6}{|l|}{ Age (years) } \\
\hline $18-24$ & 388 (59.78) & 343 (59.76) & $45(60.00)$ & 0.354 & 0.950 \\
\hline \multicolumn{6}{|l|}{ Marital status } \\
\hline Single & $509(78.43)$ & $446(77.70)$ & $63(84.00)$ & 9.918 & 0.019 \\
\hline Married & $137(21.11)$ & $126(21.95)$ & $11(14.67)$ & & \\
\hline Divorced/widowed & $2(0.31)$ & $2(0.35)$ & $0(0)$ & & \\
\hline Missing data & $1(0.15)$ & $0(0)$ & $1(1.33)$ & & \\
\hline \multicolumn{6}{|l|}{ Rank enlisted } \\
\hline Officer & $52(8.01)$ & $43(7.49)$ & $9(12.00)$ & 2.819 & 0.589 \\
\hline Non-commissioned & 451 (69.49) & 400 (69.69) & $51(68.00)$ & & \\
\hline Junior enlisted & 138 (21.26) & $123(21.43)$ & $15(20.00)$ & & \\
\hline Cadet & $7(1.09)$ & $7(1.22)$ & $0(0)$ & & \\
\hline Missing data & $1(0.15)$ & $1(0.17)$ & $0(0)$ & & \\
\hline
\end{tabular}

sex, education, marital status, rank and service length). Table 3 presents the summary of the regression analyses. Organisational barriers, not knowing the location of mental health clinics and being perceived as weak were the main barriers.

\section{DISCUSSION}

One objective of this research was to investigate the degree of the PLA Navy's willingness to seek psychological help. Encouragingly, $88.44 \%$ of the base navy personnel were willing to seek help if they had a mental health problem. This ratio was higher than that of a study deploying soldiers in the USA, ${ }^{19}$ in which $65.7 \%$ of the responding soldiers indicated that they would be willing to address a mental health condition if they thought they had an issue or if the postdeployment screening identified an ongoing problem. This may be because of the contribution of traditional ideological and political education in the Chinese PLA. The Chinese PLA was founded and led by the Communist Party of China. The political work performed by the Chinese PLA is the ideological and organisational work of the Communist Party of China within the army. The fundamental task of this type of work is to ensure the absolute leadership of the Communist Party over the military. Political work mainly includes content such as regular ideological work, ideological and political education, construction of the party organisation and construction of the cadre system. The Political Work Department consists of the General Political Department established by the Chinese PLA, Political Commissars and institutions established by organisations above the regiment level, political directors established by battalions and political instructors established by companies. Like military officers, they are also the heads of the units they serve, and jointly responsible for all types of work in their respective units, under the leadership of the same-level party committee. One of the main functions of the Political Work Department is to perform regular ideological education. The political work regulations are statutory documents that regulate the relationships among various aspects of the PLA's political work. They are also the fundamental basis for the Chinese military to perform political work. According to the regulations, the main content of regular ideological work is to address the practical mental health problems of officers and soldiers, so that ideological education can be performed in a timely manner, to maximise the effectiveness of psychological counselling. Therefore, one of the most important tasks for the Political Work Department in the Chinese military is to pay close attention to the changes in the mental health status of officers and soldiers, so that psychological counselling can be 
Table 2 Attitude and perceived barriers to mental healthcare*

\begin{tabular}{|c|c|c|c|c|c|c|c|c|}
\hline Attitude and perceived barriers & $\mathbf{n}$ & $\begin{array}{l}\text { Strongly } \\
\text { disagree }\end{array}$ & Disagree & $\begin{array}{l}\text { Neither } \\
\text { agree nor } \\
\text { disagree }\end{array}$ & Agree & $\begin{array}{l}\text { Strongly } \\
\text { agree }\end{array}$ & $\chi^{2}$ & $P$ value \\
\hline 1. I do not trust mental health professionals & 646 & 90 & 269 & 202 & 75 & 10 & 5.874 & 0.209 \\
\hline Willing to seek help & 573 & 86 & 239 & 174 & 65 & 9 & & \\
\hline Not willing to seek help & 73 & 4 & 30 & 28 & 10 & 1 & & \\
\hline 2. Mental healthcare does not work & 648 & 127 & 355 & 136 & 28 & 2 & 10.753 & 0.029 \\
\hline Willing to seek help & 573 & 119 & 316 & 115 & 21 & 2 & & \\
\hline Not willing to seek help & 75 & 8 & 39 & 21 & 7 & 0 & & \\
\hline 3. Members of my unit might have less confidence in me & 647 & 114 & 216 & 134 & 166 & 17 & 12.877 & 0.012 \\
\hline Willing to seek help & 572 & 105 & 196 & 116 & 144 & 11 & & \\
\hline Not willing to seek help & 75 & 9 & 20 & 18 & 22 & 6 & & \\
\hline 4. My unit leadership might treat me differently & 649 & 114 & 208 & 130 & 173 & 24 & 7.176 & 0.127 \\
\hline Willing to seek help & 574 & 106 & 189 & 113 & 146 & 20 & & \\
\hline Not willing to seek help & 75 & 8 & 19 & 17 & 27 & 4 & & \\
\hline 5. It would harm my career & 647 & 60 & 148 & 99 & 294 & 46 & 3.672 & 0.452 \\
\hline Willing to seek help & 572 & 53 & 132 & 82 & 264 & 41 & & \\
\hline Not willing to seek help & 75 & 7 & 16 & 17 & 30 & 5 & & \\
\hline 6. I do not know where to get help & 648 & 95 & 263 & 111 & 156 & 23 & 20.187 & $<0.001$ \\
\hline Willing to seek help & 573 & 89 & 243 & 98 & 126 & 17 & & \\
\hline Not willing to seek help & 75 & 6 & 20 & 13 & 30 & 6 & & \\
\hline 7. Mental healthcare costs too much money & 647 & 82 & 263 & 175 & 105 & 22 & 9.771 & 0.044 \\
\hline Willing to seek help & 572 & 76 & 240 & 152 & 87 & 17 & & \\
\hline Not willing to seek help & 75 & 6 & 23 & 23 & 18 & 5 & & \\
\hline 8. There would be difficulty getting time off work for treatment & 648 & 74 & 257 & 110 & 162 & 45 & 16.101 & 0.003 \\
\hline Willing to seek help & 573 & 70 & 238 & 93 & 137 & 35 & & \\
\hline Not willing to seek help & 75 & 4 & 19 & 17 & 25 & 10 & & \\
\hline 9. I do not have adequate transportation & 649 & 83 & 292 & 114 & 124 & 36 & 17.063 & 0.002 \\
\hline Willing to seek help & 574 & 80 & 267 & 97 & 101 & 29 & & \\
\hline Not willing to seek help & 75 & 3 & 25 & 17 & 23 & 7 & & \\
\hline 10. It is difficult to schedule an appointment & 648 & 78 & 206 & 227 & 108 & 29 & 10.350 & 0.035 \\
\hline Willing to seek help & 573 & 73 & 188 & 200 & 87 & 25 & & \\
\hline Not willing to seek help & 75 & 5 & 18 & 27 & 21 & 4 & & \\
\hline 11. It would be too embarrassing & 648 & 87 & 283 & 139 & 124 & 15 & 29.272 & $<0.001$ \\
\hline Willing to seek help & 573 & 83 & 255 & 128 & 98 & 9 & & \\
\hline Not willing to seek help & 75 & 4 & 28 & 11 & 26 & 6 & & \\
\hline 12. I would be seen as weak & 648 & 101 & 374 & 111 & 55 & 7 & 22.546 & $<0.001$ \\
\hline Willing to seek help & 573 & 97 & 336 & 95 & 40 & 5 & & \\
\hline Not willing to seek help & 75 & 4 & 38 & 16 & 15 & 2 & & \\
\hline
\end{tabular}

*Data excluded missing values.

Table 3 Logistic regression analyses results of demographic variables, barriers to care and willingness to seek help

\begin{tabular}{|c|c|c|c|}
\hline & & $P$ value & OR $(95 \% \mathrm{CI})$ \\
\hline \multicolumn{4}{|c|}{ Dependent variable: willingness to seek help } \\
\hline \multicolumn{4}{|l|}{ Barriers } \\
\hline \multicolumn{4}{|l|}{ Model 1} \\
\hline $\begin{array}{l}\text { 6. I do not know where to get } \\
\text { help }\end{array}$ & -0.342 & 0.005 & 0.710 (0.559 to 0.902$)$ \\
\hline 12. I would be seen as weak & -0.436 & 0.003 & $0.647(0.487$ to 0.859$)$ \\
\hline \multicolumn{4}{|l|}{ Model 2} \\
\hline $\begin{array}{l}\text { 6. I do not know where to get } \\
\text { help }\end{array}$ & -0.340 & 0.006 & 0.712 (0.560 to 0.906$)$ \\
\hline 12. I would be seen as weak & -0.426 & 0.003 & $0.653(0.491$ to 0.869$)$ \\
\hline
\end{tabular}

conducted in a timely manner. Moreover, the Health Department in the Chinese military provides mental health services to soldiers. Although the PLA introduced mental health services relatively late, the Political Work Department plays an important supporting role in mental health work. With constant ideological and political education, which is unique to China, military personnel are potentially encouraged to improve their motivation to seek mental healthcare.

The organisational barriers assessed in this study appraised whether the Chinese Navy experienced the barriers of not knowing where to seek help, the cost of mental healthcare, being unable to get time off work for treatment, not having adequate transport and being unable to get appointments. Univariate analysis suggested that all of the organisational practical barriers were endorsed as important barriers, while binary logistic regression analyses confirmed that navy personnel's willingness to seek help was impeded by a lack of knowledge regarding the location of 
mental health clinics. Though organisational barriers appeared to be important factors in preventing soldiers from seeking help, not knowing where to get help was the least frequently reported organisational barrier among US and British military personnel. ${ }^{40}$ Consistent results were obtained in a study across US, UK, Australian, New Zealand and Canadian militaries. ${ }^{21} \mathrm{~A}$ possible reason is that mental health-related programmes do not provide the same organisational support as those intended for smoking cessation, physical fitness, motor vehicle safety and alcohol awareness in the US forces. ${ }^{22}$ This reason could also have been applicable to the navy base in the present study. Compared with mental health services, ideological and political education exists for a longer period and is more significant among Chinese militaries, which may have weakened the importance of the former. Further, our previous research found that mental health education performed by the PLA mainly focused on prevention, with limited flexibility and variety. ${ }^{23}$ These findings shed light on the problem of the effectiveness of existing mental health services in military settings. There is a necessity to improve the current model of mental health services. The first step is to increase the accessibility and availability of mental health services. Furthermore, it is essential to conduct regular evaluations of the effectiveness of mental health services during provision.

In a previous study, ${ }^{1} 65 \%$ of soldiers and marines reported that receiving mental health services would cause them to be seen as weak, which was the most frequently selected barrier to mental health services. In a sample of veterans from the Operation Enduring Freedom in Afghanistan and Operation Iraqi Freedom, ${ }^{14}$ the belief that therapy is a sign of weakness was associated with a decreased likelihood in using mental health services. A meta-analysis found that the second most frequent concern of stigma items was being seen as weak. ${ }^{24}$ In this study, we found that being perceived as weak was another factor preventing participants' willingness from seeking help. The military is often perceived as a symbol of strength and health by the general public, while seeking help is a sign of weakness. The belief, 'I would be seen as weak', is also one manifestation of stigma. Corrigan ${ }^{2526}$ presented three approaches to mitigate this stigma: protest, education and promoting contact with individuals who have a mental health disorder. Greenberg $e a^{27}$ found that psychoeducational briefs may benefit psychological health. The Royal Navy has developed a trauma risk management programme, incorporating education and contact with individuals with mental disorders. ${ }^{28}$ This programme delivers psychoeducational interventions aimed toward de-stigmatising mental health problems and encouraging military personnel to seek help when they need it most, both before and after deployment. ${ }^{29}$ In the past, for Chinese military members, the content of mental health education mainly included the following: enhancing awareness of mental health problems, understanding common mental health problems, identifying elements of mental fitness, mastering methods of psychological adjustment and acquiring skills to maintain mental fitness. It is essential to deliver psychoeducation aimed at de-stigmatising mental health problems at the base. Moreover, it is critical to start, in a timely manner, developing contact with individuals who have mental health concerns.

In this study, the navy base personnel's willingness to seek help if they had a mental health problem was high. Not knowing the location of the mental health clinics, and being seen as weak, were the chief factors preventing participants' willingness to seek help. However, there are some limitations to this study. First, the data were collected using a self-report questionnaire, which raises concerns about same-source measurement bias, the deviation caused by common method variance. Common method variance can either inflate or deflate the relationship between study factors. The survey also used a Likert-style response set, which is vulnerable to the effect of response bias. However, given that individuals often view their own opinions as best, and each respondent was assured of confidentiality, a subjective report was the best approach. Furthermore, there is the possibility of social desirability bias. Soldiers tend to present their self in a favourable way rather than offering accurate answers. Second, the cross-sectional design limits inferences about causality; thus, future studies should employ longitudinal designs to investigate this topic. Third, although studies that require participants to identify factors that contribute to their decision not to seek care are certainly useful and informative, ${ }^{1}$ the association between mental health beliefs/attitudes and service use should be further studied.

\section{CONCLUSIONS}

Willingness to seek mental health services is critical to ensure the provision of necessary treatment to service members. This study provided important new findings on the willingness of active Chinese Navy members to engage in mental health services. Not knowing the location of mental health clinics and being seen as weak were the main factors preventing participants' willingness to seek help. To improve the use of mental health services, extensive efforts to decrease organisational barriers and stigma towards mental healthcare should be a priority for researchers and policymakers. Psychoeducation aimed at de-stigmatising mental health problems should be delivered and the accessibility and availability of mental health services should be increased. Our future research will investigate the status of help-seeking behaviours of the Chinese Navy in practice, which may help elucidate the relationships among barriers to seeking help, willingness to seek help and help-seeking behaviours in practice.

Contributors R-PG was a major contributor in writing the manuscript. X-FY analysed and interpreted the data. X-RL supervised the preparation, conduction and evaluation of the study.

Funding This work was supported by the Second Military Medical University (grant number 2016JS15). The sponsor had no role in study design; collection, analysis and interpretation of data; writing of the report; or the decision to submit the article for publication.

Competing interests None declared.

Patient consent for publication Not required.

Ethics approval The protocol was approved by the Institutional Ethics Review Board of the Second Military Medical University (2018LL0588). This work was approved by the East Sea Base.

Provenance and peer review Not commissioned; externally peer reviewed.

Data availability statement The datasets used and/or analysed during the current study are available from the corresponding author on reasonable request.

Open access This is an open access article distributed in accordance with the Creative Commons Attribution Non Commercial (CC BY-NC 4.0) license, which permits others to distribute, remix, adapt, build upon this work non-commercially, and license their derivative works on different terms, provided the original work is properly cited, appropriate credit is given, any changes made indicated, and the use is non-commercial. See: http://creativecommons.org/licenses/by-nc/4.0/.

\section{ORCID iD}

Ren-Ping Gu http://orcid.org/0000-0001-5855-8363

\section{REFERENCES}

1 Hoge CW, Castro CA, Messer SC, et al. Combat duty in Iraq and Afghanistan, mental health problems, and barriers to care. N Engl J Med 2004;351:13-22.

2 Blood CG, Jolly R. Comparisons of disease and nonbattle injury incidence across various military operations. Mil Med 1995;160:258-63. 
3 Hoeffler DF, Melton LJ. Changes in the distribution of navy and marine Corps casualties from World War I through the Vietnam conflict. Mil Med 1981;146:776-9.

4 Croft AM, Hoad NA, Dale RF. Hospitalization of British troops during operation joint endeavor (Bosnia). Mil Med 1999:164:460-5.

5 Writer JV, DeFraites RF, Keep LW. Non-Battle injury casualties during the Persian Gulf War and other deployments. Am J Prev Med 2000;18:64-70.

6 Cohen SP, Brown C, Kurihara C, et al. Diagnoses and factors associated with medical evacuation and return to duty for service members participating in operation Iraqi freedom or operation enduring freedom: a prospective cohort study. Lancet 2010;375:301-9.

7 Milliken CS, Auchterlonie JL, Hoge CW. Longitudinal assessment of mental health problems among active and reserve component soldiers returning from the Iraq war. JAMA 2007:298:2141-8.

8 Wright $\mathrm{KM}$, Huffman $\mathrm{AH}$, Adler $\mathrm{AB}$, et al. Psychological screening program overview. Mil Med 2002;167:853-61.

9 Aakre JM, Himelhoch S, Slade EP. Mental health service utilization by Iraq and Afghanistan Veterans after entry into PTSD specialty treatment. Psychiatr Serv 2014;65:1066-9.

10 Hoge CW, Grossman SH, Auchterlonie JL, et al. Ptsd treatment for soldiers afte combat deployment: low utilization of mental health care and reasons for dropout. Psychiatr Serv 2014;65:997-1004.

11 Britt TW, Greene-Shortridge TM, Brink S, et al. Perceived stigma and barriers to care for psychological treatment: implications for reactions to stressors in different contexts. J Soc Clin Psychol 2008;27:317-35.

12 Chapman PL, Elnitsky C, Pitts B, et al. Mental health, help seeking, and stigma and barriers to care among 3- and 12-month postdeployed and never deployed U.S. Army combat Medics. Mil Med 2014;179:55-62.

13 Kim PY, Thomas JL, Wilk JE, et al. Stigma, barriers to care, and use of mental health services among active duty and national guard soldiers after combat. Psychiatr Serv 2010;61:582-8.

14 Pietrzak RH, Johnson DC, Goldstein MB, et al. Perceived stigma and barriers to menta health care utilization among OEF-OIF veterans. Psychiatr Serv 2009;60:1118-22.

15 Jones N, Keeling M, Thandi G, et al. Stigmatisation, perceived barriers to care, help seeking and the mental health of British military personnel. Soc Psychiatry Psychiatr Epidemiol 2015;50:1873-83.
16 Liu W, Xue C, YP L, et al. Investigation of healthcare demands of PLA soldiers in the island of the South China Sea. Academic Journal of Second Military Medical University 2016;37:1415-7.

17 Zhu WY, Li X, Xia J, et al. Prevalence of anxiety/depression among navy officers and men during long navigation and influencing factors thereof. Chin J EmergResusc Disaster Med 2017:12:247-9.

18 Shuai $\mathrm{L}, \mathrm{CY} 0, \mathrm{ZQ}$ X, et al. Study on the health seeking behavior of navy servicemen and its influencing factors. Hosp Admin J Chin PLA 2018;25:230-4.

19 Warner CH, Appenzeller GN, Mullen K, et al. Soldier attitudes toward mental health screening and seeking care upon return from combat. Mil Med 2008;173:563-9.

20 Osório C, Jones N, Fertout M, et al. Perceptions of stigma and barriers to care among UK military personnel deployed to Afghanistan and Iraq. Anxiety Stress Coping 2013:26:539-57.

21 Gould M, Adler A, Zamorski M, et al. Do stigma and other perceived barriers to mental health care differ across armed forces? J R Soc Med 2010;103:148-56.

22 Westphal RJ. Discourse analysis of Navy leaders' attitude about mental health problems (doctoral dissertation. Charlottesville, VA: University of Virginia, Department of Nursing, 2004

23 Renping GU, Youran Jl, Fei XU, et al. Investigation of mental health education of PLA. Hosp Admin J Chin PLA 2017;24:965-7.

24 Sharp M-L, Fear NT, Rona RJ, et al. Stigma as a barrier to seeking health care among military personnel with mental health problems. Epidemiol Rev 2015:37:144-62.

25 Corrigan PW, Penn DL. Lessons from social psychology on discrediting psychiatric stigma. Am Psychol 1999:54:765-76.

26 Corrigan P. How stigma interferes with mental health care. Am Psychol 2004;59:614-25.

27 Greenberg N, Langston V, Fear NT, et al. An evaluation of stress education in the Roya Navy. Occup Med 2009:59:20-4.

28 Jones N, Roberts P, Greenberg N. Peer-group risk assessment: a post-traumatic management strategy for hierarchical organizations. Occup Med 2003:53:469-75.

29 Gould M, Greenberg N, Hetherton J. Stigma and the military: evaluation of a PTSD psychoeducational program. J Trauma Stress 2007:20:505-15. 